Tohoku J. Exp. Med., 2003, 199, 43-48

\title{
A Noncarcinogenic Small Dose of $n$-Methylnitrosourea Enhances Colon Tumorigenesis in F344 Rats
}

\author{
TOMio Narisawa and Yoko Fukaura \\ Akita University College of Allied Medical Sciences, Akita 010-8543
}

\begin{abstract}
Narisawa, T. and Fukaura, Y. A Noncarcinogenic Small Dose of $n$ Methylnitrosourea Enhances Colon Tumorigenesis in F344 Rats. Tohoku J. Exp. Med., 2003, 199(1), 43-48 — Very small amount of carcinogens such as nitroso compounds and heterocyclic amines has been found in human feces. This study was designed to investigate in F344 rats whether an intrarectal noncarcinogenic small dose of $n$-methylnitrosourea $(0.2 \mathrm{mg}, 3$ times weekly) affects colon carcinogenesis initiated with an intrarectal large dose ( $2 \mathrm{mg}, 3$ times weekly) of this carcinogen. The colon tumor yield at week 50 in 12 rats receiving the large dose for 2 weeks and then the small dose for the next 30 weeks significantly increased as compared to 23 rats receiving only the large dose for 2 weeks: $100 \%$ vs. $70 \%$ in tumor incidence and 4.3 vs. 1.2 in mean number of tumors per rat. No tumors were found in 12 rats receiving only the small dose for 30 weeks. The results indicate that a very small amount of carcinogens could participate in a tumorenhancing effect on the high-risk colon induced with a large dose of carcinogens, even though their less amounts insufficient to complete carcinogenesis process. Further study is needed to elucidate if administration of such a small dose could induce epigenetic alterations or further genetic changes in the initiated colonic cells. colon cancer; $n$-methylnitrosourea; rat
\end{abstract}

(C) 2003 Tohoku University Medical Press

Animal models for colon carcinogenesis have been developed by treatments with subcutaneous injection of colon-specific carcinogens such as 1,2-dimethylhydrazine (DMH) and azoxymethane (AOM) (Druckrey et al. 1967; Druckrey 1972; Rogers and Nauss 1985), dietary administration of heterocyclic amines such as 2-amino-3-methylimidazo[4,5-f]-quinoline (IQ) and 2-amino-1-methyl-6-phenylimidazo [4,5-b] pyridine (PhIP) (Takayama et al. 1984; Ito et al. 1991), and intrarectal instillation of directacting carcinogens such as N-methyl- $\mathrm{N}^{\prime}$-nitro-Nnitrosoguanidine (MNNG) and $n$ methylnitrosourea (MNU) (Narisawa et al. 1971, 1976) in rats and mice. These agents effectively induce tumors specifically in the colon, and histopathology of these tumors have similarities with human colon tumors. However, it should

Received October 22, 2002; revision accepted for publication January 28, 2003.

Present address for Tomio Narisawa, M.D., Kurakakenosato, Tsurunumadai 43-231, Tennoh-machi, Akita 010-0201, Japan.

e-mail: kurakake@ violin.ocn.ne.jp 
be recognized that the doses used to induce the tumors in these models are extremely large, and that the tumor incidence exceeds $50 \%$. The large dosage affects the colonic cells as tumor initiator which induces genetic alterations in oncogenes and tumor suppressor genes at the first step of carcinogenesis. On the other hand, it is well known that several carcinogens which are classified as complete carcinogens also act as tumor promoters resulting in epigenetic changes in initiated cells and progressive disregulation of cell proliferation (Miller and Miller 1981). Possible colon carcinogens in humans such as N-nitroso compounds and heterocyclic amines have been found in the feces. However, they are far below the concentration for tumor initiation of the colonic cells (Wakabayashi et al. 1992; Bingham et al. 1996). Bingham et al. (1996) confirmed that endogenous production of N-nitroso compounds in the colon of the high risk diet-fed subjects was $113 \mu \mathrm{g} /$ day on average. Suzuki and Mitsuoka (1981) reported that fecal nitrosamines increased in Japanese individuals given a Western type diet, and the maximum total amount was $2.66 \mu \mathrm{g} / 100 \mathrm{~g}$ feces. Augustsson et al. (1999) estimated that daily intake of heterocyclic amines in Swedish people with the usual diet was less than $100 \mathrm{ng} /$ day. Thus, it is important to know whether such very small amount of carcinogens (a noncarcinogenic dose) below the dosage for tumor initiation exerts any effect on colon carcinogenesis.

The present study was designed to investigate whether intrarectal administration of a noncarcinogenic small dose of MNU, which is not exhibit colon tumor development, could contribute to colon carcinogenesis in an animal model. The results indicated that the longterm administration of one-tenth $(0.2 \mathrm{mg})$ of a usual carcinogenic large dose (2 mg) of MNU, which was given during the post-initiation period, significantly increased the colon cancer development after initiation with the usual large dose of MNU.

\section{MATERIALS AND METHOdS}

Female F344/NSlc rats (Shizuoka Laboratory Animal Center, Hamamatsu), 7 weeks of age at the start of experiment, were used. They were housed, 4 rats per cage, in plastic cages with sterilized wood-chip bedding in a specific-pathogen-free room that was maintained under controlled conditions $\left(2^{\circ} \mathrm{C}\right.$ and $50 \%$ relative humidity) with a 12 hours light and dark cycle. They had free access to a standard pelleted chow CE-2 (CLEA Co., Tokyo) and drinking water. The body weights were measured once a week throughout the study. The rats were maintained according to the standards set forth in the Guidelines for the Care and Use of Laboratory Animals of the Experimental Animal Facility, Akita University School of Medicine. MNU was obtained from Nacalai Tesque, Kyoto. A total number of 88 rats were divided into 7 groups of 24,12 or 8 rats each. The rats were treated intrarectally with $0.5 \mathrm{ml}$ of $0.4 \% \mathrm{MNU}$ solution (a large dose of $2 \mathrm{mg}$ MNU), $0.5 \mathrm{ml}$ of $0.04 \% \mathrm{MNU}$ solution (a small dose of $0.2 \mathrm{mg} \mathrm{MNU}$ ) or 0.5 $\mathrm{ml}$ of vehicle $(0.9 \% \mathrm{NaCl}$ solution) 3 times a week for the period described below. The solutions were freshly prepared immediately before use, and the solutions were injected through a metal feeding tube $8 \mathrm{~cm}$ long which was inserted two-thirds into the colon lumen through the anal orifice. The solution filled the distal half of the colon where the tumors developed. Group 1 (24 rats) received only a large dose of MNU at weeks 1 and 2; Group 2 (12 rats) received a large dose of MNU at weeks 1 and 2, and then a small dose of MNU during weeks 3 and 7; Group 3 (12 rats) received a large dose of MNU at weeks 1 and 2, and then a small dose of MNU during weeks 3 and 32; Groups 4 (8 rats) received a large dose of MNU at weeks 1 and 2, and then a dose of vehicle during weeks 3 and 7; Group 5 (8 rats) received a large dose of MNU at weeks 1 and 2 , and then a dose of vehicle during weeks 3 
and 32; Group 6 (12 rats) received a dose of vehicle at weeks 1 and 2, and then a small dose of MNU during weeks 3 and 32; Group 7 (12 rats) received only a dose of vehicle during weeks 1 and 32. No other treatment was given to rats in all the groups until week 50 when the experiment was terminated, and all the rats were killed by $\mathrm{CO}_{2}$ asphyxiation as scheduled.

At autopsy the colons were excised, cut open along their length, and inspected macroscopically for tumor occurrence. The location, shape and size of colon tumors were recorded. All colon tumors and macroscopically abnormal tissues or organs were examined microscopically after standard processing, sectioning and staining with hematoxylin and eosin. One rat in the group 1 dead early was excluded from the present study.

The colon tumor incidence (number of tumor-bearing rats per number of rats examined) and multiplicities (number of tumors per rat and number of tumors per tumor- bearing rat) were evaluated statistically by Fisher's exact probability test and Mann-Whitney's U-test, respectively. Differences were considered statistically significant at $p<0.05$.

\section{RESULTS}

The body weights of rats were comparable in all groups. The mean body weight in each group ranged from 102 to $104 \mathrm{~g}$ at week 1, and from 261 to $265 \mathrm{~g}$ at week 50 .

The incidence and multiplicity of colon tumors at week 50 were summarized in Table 1. The incidences in rats which received only a large dose of MNU for 2 weeks (Group 1) and a large dose of MNU for 2 weeks followed by vehicle for 5 weeks or 30 weeks (Groups 4 and 5) were mostly the same: $70 \%, 63 \%$ and $75 \%$, while the treatment with a small dose of MNU only (Group 6) as well as vehicle only (Group 7) for the long-term of 30 weeks did not induce any tumors. On the other hand, it was remarkable that the incidence in rats which received a large dose for 2 weeks followed by a small dose for 5 weeks (Group 2) or for 30 weeks (Group 3) was 100\%. This incidence was significantly higher

TABLE 1. Colon tumor development induced with intrarectal administration of a large dose (2 mg) and/or a small dose $(0.2 \mathrm{mg})$ of n-methylnitrosourea in F344 rats

\begin{tabular}{ccccc}
\hline $\begin{array}{c}\text { Treatment } \\
\text { groups }\end{array}$ & $\begin{array}{c}\text { No. of rats } \\
\text { examined }\end{array}$ & $\begin{array}{c}\text { No. of rats } \\
\text { with tumors }\end{array}$ & $\begin{array}{c}\text { No. of tumors } \\
\text { per rat }\end{array}$ & $\begin{array}{c}\text { No. of tumors per } \\
\text { tumor-bearing rat }\end{array}$ \\
\hline 1 & 23 & $16(70 \%)$ & $1.2 \pm 1.1^{\mathrm{b}}$ & $1.7 \pm 1.0^{\mathrm{b}}$ \\
2 & 12 & $12(100 \%)^{\mathrm{c}}$ & $2.0 \pm 1.2$ & $2.0 \pm 1.2$ \\
3 & 12 & $12(100 \%)^{\mathrm{c}}$ & $4.3 \pm 1.7^{\mathrm{d}}$ & $4.3 \pm 1.7^{\mathrm{d}}$ \\
4 & 8 & $5(63 \%)$ & $0.8 \pm 0.7$ & $1.2 \pm 0.4$ \\
5 & 8 & $6(75 \%)$ & $1.1 \pm 0.8$ & $1.5 \pm 0.5$ \\
6 & 12 & 0 & 0 & 0 \\
7 & 12 & 0 & 0 & 0 \\
\hline
\end{tabular}

${ }^{\mathrm{a}}$ Group 1 received 3 times weekly a large dose of MNU at weeks 1-2, Groups 2 and 3 a large dose of MNU at weeks 1-2, then a small dose of MNU for weeks 3-7 and weeks 3-32, respectively, Groups 4 and 5 a large dose of MNU at weeks 1-2, then a vehicle dose $(0.5 \mathrm{ml}$ of $0.9 \% \mathrm{NaCl}$ solution) for weeks $3-7$ and weeks $3-32$, respectively, Group 6 a vehicle dose at weeks 1-2, then a small dose of MNU for weeks 3-32, and Group 7 a vehicle dose for weeks 1-32. All rats were sacrificed and examined for tumor development at week 50 .

${ }^{b}$ Mean \pm s.D. $\quad$ 'Significantly different from groups 1, 4, 6 and 7: $p<0.05$.

${ }^{\mathrm{d} S}$ Significantly different from all other groups: $p<0.01$. 
than those of Groups 1 and 4. It was also higher than that of Group 5, but the difference did not reach statistical significance $(0.1>p>0$. 05). In addition, administration of a large dose for 2 weeks followed by a small dose for 30 weeks (Group 3) significantly increased the colon tumor multiplicities in terms of the number of tumors per rat and the number of tumors per tumor-bearing rat as compare to other treatments (Groups 1, 2, 4 and 5). Administration of a large dose for 2 weeks plus a small dose for 5 weeks only (Group 2) also increased, but not significantly, the tumor multiplicities. It was noted again that the tumor multiplicities showed to be significantly different between the Groups 2 and 3.

The tumors were located diffusely in the distal half of the colon about 0 to $9 \mathrm{~cm}$ proximal from the anus, and were either plaque-shaped or polypoid. Histologically all the tumors were differentiated adenocarcinomas, except one signet-ring cell carcinoma in Group 2 which is 5 $\mathrm{mm}$ in diameter and invading into the proper muscle. Most of the tumors were less than 8 $\mathrm{mm}$ in diameter except two tumors in Group 3, and were restricted to the mucosa or submucosa; but one tumor in Group 2, and 7 tumors in Group 3 were invading into the proper muscle or serosa (Table 2). However, no significant differences were assessed in the size and invasion of tumors among groups. No metastases to lymph nodes and other organs were observed. There were no other path- ologic findings in the gastrointestinal tract or other organs in any groups.

\section{DISCUSSION}

The present results clearly demonstrated that a noncarcinogenic intrarectal small dose of MNU (0.2 mg) enhanced colon carcinogenesis initiated with a carcinogenic intrarectal large dose of MNU (2 mg), as increased the tumor yield in incidence and multiplicity in Groups 2 and 3. To our knowledge, there were no reports on tumor enhancing effect of a noncarcinogenic small dose of colon carcinogens. In animal models for colon carcinogenesis, two types of chemical carcinogens have been used to induce colon tumors in rodents, one directly acting and not requiring metabolic activation (e. g., MNU and MNNG), and the other requiring metabolic activation (e.g., $\mathrm{DMH}, \mathrm{AOM}$ and heterocyclic amines). Carcinogens requiring metabolic activation are activated in the liver, transported to the colon via the bile, small intestine and fecal stream, and undergo final activation by microflora in the colon lumen (Rogers and Nauss 1985; Wakabayashi et al. 1992). A single intragastric large dose of MNU induces adenomas in the colon of rats (Leaver et al. 1969), perhaps by the direct action of a small part of MNU which is transported into the colon via the fecal stream. In the present study, MNU, which was instilled into the colon lumen and could affect the colon mucosa through direct contact, was used as a carcino-

TABLE 2. Number of colon tumors in size and depth of invasion

\begin{tabular}{|c|c|c|c|c|c|c|c|}
\hline \multirow{2}{*}{$\begin{array}{l}\text { Treatment }^{\mathrm{a}} \\
\text { groups }\end{array}$} & \multirow{2}{*}{$\begin{array}{l}\text { Total number } \\
\text { of tumors }\end{array}$} & \multicolumn{3}{|c|}{ Size in diameter ${ }^{\mathrm{b}}$} & \multicolumn{3}{|c|}{ Depth of invasion ${ }^{\mathrm{b}}$} \\
\hline & & $\sim 4 \mathrm{~mm}$ & $\sim 8 \mathrm{~mm}$ & $\sim 13 \mathrm{~mm}$ & mucosa & submucosa & muscle $\sim$ serosa \\
\hline 1 & 27 & 19 & 8 & 0 & 19 & 8 & 0 \\
\hline 2 & 24 & 20 & 4 & 0 & 18 & 5 & 1 \\
\hline 3 & 51 & 44 & 5 & 2 & 32 & 12 & 7 \\
\hline 4 & 6 & 5 & 1 & 0 & 5 & 1 & 0 \\
\hline 5 & 9 & 7 & 2 & 0 & 4 & 5 & 0 \\
\hline
\end{tabular}

${ }^{\text {aSee }}$ Table 1 or text.

${ }^{\mathrm{b}} \mathrm{No}$ significant difference among groups. 
gen to induce colon tumors because this carcinogen is particularly useful to distinguish local effect without undergoing metabolic activation.

Rat colon cancer induced with an intrarectal large dose of MNU revealed to have mutated K-ras gene, although its defined frequency was low as 30\% (Jacoby et al. 1992). Intrarectal MNNG-induced rat colon cancer expressed mutated p53 protein in the nucleus at high frequency of $50 \%-60 \%$ (Tendler et al. 1994). Also, intracolonic administration of MNU induced the formation of DNA adducts, 7-methylguanine and $\mathrm{O}^{6}$-methylguanine, which is considered a promutagenic change, and the appearance of preneoplastic lesions, aberrant crypt foci, in the colon mucosa of rats at dose dependent manner (Qin et al. 1994). However, the treatment with the solution at the lowest concentration $(3.0 \mathrm{ml}$ of $1.5 \mathrm{mM}$ solution, or $0.45 \mathrm{mg}$ of MNU) failed significant appearance of the lesions. In the present study, intrarectal small dose of MNU (0.2 mg) alone did not produce any tumors even though the long-term administration for 30 weeks and then the long period of observation of 20 weeks. In our previous study (Reddy et al. 1975), intrarectal administration of MNNG at dose levels of 1.25 $\mathrm{mg}$ to $0.313 \mathrm{mg}$ twice weekly for 50 weeks exhibited a steep dose-response on colon tumor development in rats, and no colon tumor development was observed in $0.313 \mathrm{mg}$ MNNG treatment group. Also, intrarectal dose of MNU displayed rat colon tumor development in doseresponse fashion (Ward et al. 1978). However, there were no studies on long-term treatment with such noncarcinogenic small dose levels of MNU.

Recently, hypermethylation of $\mathrm{CpG}$ island in promoter area of tumor suppressor genes and mismatch repair genes (e.g., p16 and hMLH1), and subsequent gene inactivation via a silencing of gene transcription has been attracted a great deal of notice as a mechanism of tumorigenesis including colon cancer in humans (Deng et al. 1999; Guan et al. 1999; Tycko 2000). Such non-mutational epigenetic alteration can play an important role in the formation and progression of colon cancer. Thus, it is concluded that additional studies are needed to clarify the underlying mechanisms, that is, further genetic changes or epigenetic alterations, responsible for the tumor enhancing effect by a small dose of MNU as demonstrating in the present study.

\section{Acknowledgments}

The authors thank Mr. Kazumi Toita for his excellent technical assistance.

\section{References}

Augustsson, K., Skog, K., Jaegerstad, M., Dickman, P.W. \& Steineck, G. (1999) Dietary heterocyclic amines and cancer of the colon, rectum, bladder and kidney: a population- based study. Lancet, 353, 703-707.

Bingham, S.A., Pignatelli, B., Pollock, J.R.A., Ellul, A., Malaveille, C., Gross, G., Rinswick, S., Cummings, J.H. \& O’Neil, I.K. (1996) Does increased endogenous formation of $\mathrm{N}$-nitroso compounds in the human colon explain the association between red meat and colon cancer? Carcinogenesis, 17, 515-523.

Deng, G., Chen, A., Hong, J., Chae, H.S. \& Kim, Y.S. (1999) Methylation of CpG in a small region of the hMLH1 promoter invariably correlates with the absence of gene expression. Cancer Res., 59, 2029-2033.

Druckrey, H., Preussmann, R., Matzkies, F. \& Ivankovic, S. (1967) Selective Erzeugung von Darmkrebs bei Ratten durch 1,2Dimethylhydrazin. Naturwissenschaften, 54, 285-286.

Druckrey, H. (1972) Organospecific carcinogenesis in the digestive tract. In: Topics in Chemical Carcinogenesis, edited by W. Nakahara, S. Takayama, T. Sugimura \& S. Odashima, University of Tokyo Press, Tokyo, pp. 73103.

Guan, R.J., Fu, Y., Holt, P.R. \& Pardee, A.B. (1999) Association of K-ras mutations with p16 methylation in human colon cancer. Gastroenterology, 116, 1063-1071.

Ito, N., Hasegawa, R., Sano, M., Tamano, S., Esumi, H., Takayama, S. \& Sugimura, T. (1991) A new colon and mammary carcinogen in cooked food, 2-amino-1-methyl-6-phenyl- imidazo 
[4,5-b] pyridine (PhIP). Carcinogenesis, 12, 1503-1506.

Jacoby, R.F., Alexander, R.J., Raicht, R.F. \& Brasitus, T.A. (1992) K-ras oncogene mutations in rat colon tumors induced by N-methylN-nitrosourea. Carcinogenesis, 13, 45-49.

Leaver, D.D., Swann, P.F. \& Magee, P.N. (1969) The induction of tumors in the rat by a single oral dose of n-nitrosomthylurea. Br. J. Cancer, 23, 177-187.

Miller, E.C. \& Miller, J.A. (1981) Mechanisms of chemical carcinogenesis. Cancer, 47, 10551064.

Narisawa, T., Sato, T., Hayakawa, M., Sakuma, A. \& Nakano, H. (1971) Carcinoma of the colon and rectum of rats by rectal infusion of N-methyl-N'-nitro-N-nitrosoguanidine. Gann, 62, 231-234.

Narisawa, T., Wong, C.Q., Maronpot, R.R. \& Weisburger, J.H. (1976) Large bowel carcinogenesis in mice and rats by several intrarectal doses of methylnitrosourea and negative effect of nitrite plus methylurea. Cancer Res., 36, 505-510.

Qin, X., Zarkovic, M., Nakatsuru, Y., Arai, M., Oda, H. \& Ishikawa, T. (1994) DNA adduct formation and assessment of aberrant crypt foci in vivo in the rat colon mucosa after treatment with N-methyl-N-nitrosourea. Carcinogenesis, 15, 851-855.

Reddy, B.S., Narisawa, T., Maronpot, R., Weisburger, J.H. \& Wynder, E.L. (1975) Animal models for the study of dietary factors and cancer of the large bowel. Cancer Res., 35, 3421-3426.

Rogers, A.E. \& Nauss, K.M. (1985) Rodent models for carcinoma of the colon. Digest. Dis. Sci., 30, 87s-102s.

Suzuki, K. \& Mitsuoka, T. (1981) Increase in faecal nitrosamines in Japanese individuals given a Western diet. Science, 294, 453-456.

Takayama, S., Nakatsuru, Y., Masuda, M., Ohgaki, H., Sato, S. \& Sugimura, T. (1984) Demonstration of carcinogenicity in F344 rats of 2-amino-3-methylimidazo [4, 5-f]-quinoline from broiled sardine, fried beef and beef extract. Gann, 75, 467-470.

Tendler, Y., Reshef, R., Cohen, I., Barzilai, M., Shasha, S.M., Rotter, V. \& Shkolnik, T. (1994) Histochemical studies of progressive p53 mutations during colonic carcinogenesis in Sprague-Dawley rats induced by $\mathrm{N}$-methyl- $\mathrm{N}^{\prime}$ nitro-N-nitrosoguanidine or azoxymethane. Pathobiol., 62, 232-237.

Tycko, B. (2000) Epigenetic gene silencing in cancer. J. Clin. Invest., 105, 401-407.

Wakabayashi, K., Nagao, M., Esumi, H. \& Sugimura, T. (1992) Food-derived mutagens and carcinogens. Cancer Res., 52, 2092s-2098s.

Ward, J.M., Sporn, M.B., Wenk, M.L., Smith, J.M., Feeser, D. \& Dean, R.J. (1978) Dose response to intrarectal administration of $\mathrm{N}$-methyl-Nnitrosourea and histopathologic evaluation of the effect of two retinoids on colon lesions induced in rats. J. Natl. Cancer Inst., 60, 1489-1493. 